Artigos/Articles

\title{
Emília, a cidadã-modelo soviética: Como a obra infantil de Monteiro Lobato foi traduzida na URSS
}

Emilia, the model Soviet citizen: how the children's works of Monteiro Lobato were translated in the URSS

\author{
Marina Fonseca Darmaros \\ John Milton ${ }^{2,3}$
}

RESUMO

Este artigo analisa a tradução feita na União Soviética de As Reinações de Narizinho (1961) Orden jioltogo diatla (1961) (em português, "Ordem do Pica-Pau Amarelo"), que também inclui trechos de Memórias de Emília. Para ser publicada a tradução teve que sofrer várias mudanças: referências à propriedade particular foram alteradas; o comportamento das personagens ganhou tom educacional e moralizante; críticas aos historiadores e filósofos foram cortadas; e comentários sobre Tia Nastácia hoje em dia considerados racistas precisaram ser amenizados. Além

1. Universidade de São Paulo - USP. São Paulo - Brasil. http://orcid.org/0000-0002-91027748. E-mail: marinadarmaros@gmail.com.

2. Universidade de São Paulo - USP. São Paulo - Brasil. https://orcid.org/0000-00021329-6336. E-mail: jmilton@usp.br.

3. Meu primeiro artigo sobre as traduções de Lobato foi publicado na DELTA: "Monteiro Lobato and Translation: 'Um País se Faz com Homens e Livros"', No. 19: Especial - 2003, PUC-SP, org. John Robert Schmitz e Maria Aparecida Caltabiano, pp. 117-132. Parece apropriado que, nesta homenagem a John Schmitz, também publique um texto sobre Lobato, desta vez, junto com Marina Darmaros. 
disso, todas as referências às figuras hollywoodianas que visitam o sítio foram omitidas.

Palavras chaves: Monteiro Lobato em russo; Literatura infanto-juvenil soviética; As Reinações de Narizinho; Emília de Lobato; Adaptação.

\begin{abstract}
This article analyzes the translation of As Reinações de Narizinho (1961; Orden jioltogo diatla, "Order of the Yellow Woodpecker") published in the Soviet Union in 1961, which includes excerpts from Memórias de Emília. Several changes to the original were required in the translation: references to private property had to be cut; the behaviour of the characters had to have an educational and moralizing tone; criticism of historians and philosophers had to be omitted; and comments about Aunt Nastasia nowadays often considered racist had to be toned down. In addition, all references to Hollywood figures who visit the Sítio were removed.
\end{abstract}

Keywords: Monteiro Lobato in Russian; Soviet children's literature; As Reinações de Narizinho; Lobato’s Emília; Adaptação.

\section{Introdução}

A obra de Monteiro Lobato (1882-1948) foi vertida para um grande número de línguas, mas em geral essas traduções compuseram coletâneas esparsas de contos em francês, inglês, árabe, espanhol, alemão, japonês, ídiche, italiano (Cavalheiro 1955:565). Foi somente na Argentina que a tradução de sua obra infantil ficou amplamente conhecida. Ali, alguns de seus livros infantis foram editados diversas vezes e, em 1947, a Editorial Americalee lançou 23 volumes das Obras Completas Infantis de Monteiro Lobato traduzidas para o espanhol. É interessante, porém, notar que vários dos livros infantis de Lobato foram publicados também em um país tão distante - e de língua tão distinta - como a União Soviética. O objetivo deste artigo é examinar a tradução dessas obras para o russo e analisar por que elas foram vertidas a essa língua. 


\section{Lobato Comunista?}

Por que os livros de Lobato foram publicados na União Soviética? Primeiro, porque boa parte da obra do escritor reflete seu posicionamento, de um lado, contrário às oligarquias, aos trustes estrangeiros, ao status quo, aos poderosos e à Igreja Católica, e, de outro, a favor do desenvolvimento nacional petrolífero e siderúrgico e da reforma agrária.

Os comentários e a moral no fim de várias das Fábulas (1921/1962) mostram um Lobato socialista, contrário ao opressor e favorável a uma sociedade mais igualitária para todos. Por exemplo, em "O Cavalo e o Burro" (Lobato 1962:140-141), o primeiro se recusa a ajudar o segundo a carregar uma parte de seu fardo. O burro desmorona e, quando os tropeiros chegam, colocam todo seu fardo em cima do cavalo. Dona Benta diz que isso demostra uma falta de solidariedade da parte do cavalo e, com uma insólita referência a Deus, explica a mensagem cristã da fábula, de solidariedade, elucidando aos picapauzinhos: "É o reconhecimento de que temos de nos ajudar uns aos outros para que Deus nos ajude. Quem só cuida de si, de repente se vê sozinho e não encontra quem o socorra. Aprendam." (Lobato 1962:141)

Além disso, Lobato mostra como o trabalho é, muitas vezes, realizado em benefício de outros, que se aproveitam daqueles que o executam. Em "A Mosca e a Formiguinha" (Lobato 1962:99-101), a primeira, "fidalga", sempre se aproveita da comida dos outros. Mas, para a formiga trabalhadora, aquela é uma parasita e, no final da fábula, a mosca encontra-se trancada dentro de casa sem nada para comer, morrendo de fome. A moral é: Quem quer colher, planta. E quem do alheio vive, um dia se engasga. (Lobato 1962:100)

Em "Os Animais e a Peste" (Lobato 1962: 91-93), aqueles decidem quem será sacrificado para que o coletivo se livre da peste. O leão, a raposa e o tigre admitem os crimes que praticaram ao matar animais desprezíveis, enquanto o burro confessa ter cometido um único:

"A consciência só me acusa de haver comido uma folha de couve na horta do senhor vigário."

Os animais entreolhavam-se. Era muito sério aquilo. A raposa toma a palavra: 
"Eis, amigos, o grande criminoso! Tão horrível o que ele nos conta, que é inútil prosseguirmos na investigação. A vítima a sacrificar-se aos deuses não pode ser outra, porque não pode haver crime maior do que furtar a sacratíssima couve do senhor vigário.

Aos poderosos tudo se desculpa; aos miseráveis nada se perdoa. (Lobato 1962:92)

Dona Benta ainda comenta: "Retrata as injustiças da justiça humana. A tal justiça é implacável contra os fracos e pequeninos - mas não é capaz de pôr as mãos num grande, num poderoso". É preciso aqui realçar a sátira religiosa, com a gravidade do crime do burro em comer uma folha de couve justamente do vigário.

Em seu artigo "Monteiro Lobato e o Partido Comunista do Brasil", Osvaldo Bertolino descreve o contato que o escritor teve com o PCB. Quando Lobato esteve preso na Casa de Detenção de São Paulo, em 1941, ficou em uma cela com o comunista José Maria Crispim, com quem aprendeu muito sobre o comunismo. Além disso, teve bastante contato com Luís Carlos Prestes, por quem tinha grande admiração, apoiava muitas das ideias do PCB e admirava o grande progresso alcançado na União Soviética.

Em seu livro Mister Slang e o Brasil - colóquios com o inglês da Tijuca (1927), Lobato imagina um futuro em que Prestes seria louvado no Brasil: "Tomei um bonde e remergulhei-me na cidade dos monumentos e revoltosos, calculando de mim para mim onde iria erguer-se em anos futuros a estátua do Marechal Prestes" (Lobato 2008: 134). No artigo "O padrão", publicado em 1928, ele lamentava que o presidente Washington Luis não houvesse contemplado seu grandioso plano, pondo no Ministério da Guerra o famoso comandante da "Coluna Prestes". Em "A cegueira naval”, ainda, ele escreveu que o capitão Prestes, mesmo "nu”, sem recursos, era general (Bertolino, 2012). Já doente, Lobato não pôde comparecer ao comício do Pacaembu, em 15 de julho de 1945, que homenageou Prestes. Mas fez, de sua residência, por telefone, uma saudação ao líder comunista, enfatizando a divisão social no Brasil.

O nome de Lobato foi anunciado na chapa apresentada pelo Comitê Estadual paulista do PCB, já na legalidade desde outubro de 1945, para 
as eleições de dezembro de 1945. Porém, ele mandou retirar seu nome da chapa, dizendo estar velho e cansado demais para uma carreira política - e, provavelmente, sabendo que não conseguiria seguir a linha bastante dura do PCB. Além disso, criticava severamente o fato de que o PCB havia feito aliança com um velho inimigo seu, o Presidente Getúlio Vargas. Outra razão importante para a rejeição foi o grande entusiamo de Lobato pelo georgismo, que destacava o Imposto sobre o Valor da Terra. Assim, respeitando a propriedade particular, não haveria possibilidade de Lobato apoiar esta linha política sendo membro do Partido Comunista (Lobato 1948 apud Dallari,1994).

Apesar de Lobato nunca ter aceitado nenhum convite para ingressar no Partido Comunista, o escritor gozava de simpatia da agremiação e, assim, era "acusado" de comunista, como aponta Ênio Silveira:

O Lobato era, entre outras coisas fascinantes, acusado de comunista; ele não era propriamente comunista, mas simpatizava com o partido. Ele foi muito atacado pela Igreja, o Lobato foi muito acusado. Não era membro do partido, mas era muito amigo de comunistas e sempre esteve ao lado do partido nos momentos mais difíceis. (Ferreira; Almeida, 1992: 44-45)

Entretanto, parecia que as ideias de Lobato eram suficientemente próximas às normas soviéticas para que parte de sua obra infantil fosse traduzida. Na Seção 6, mostramos quais mudanças precisaram ser realizadas nas traduções para que a publicação de Lobato fosse aceitável em russo.

\section{Literatura Infantil Política}

É bastante comum que autores, tradutores e adaptadores de literatura infantil manipulem os textos para que estes se conformem com certa visão de mundo. Vários estudos demonstram que a tradução de livros infanto-juvenis é influenciada pela ideologia vigente no país para o qual as traduções são feitas (Shavit 1986; Klingberg 1986; Lathey 2010).

De acordo com Judith Inggs (2015:1): "A literatura infantil traduzida tende a refletir o que é considerado apropriado ou aceitável para 
uma criança em determinado contexto histórico e social e fornece a compreensão de atitudes e normas predominantes em uma sociedade". Citando Zohar Shavit, que aplicava a teoria de polissistemas à literatura infanto-juvenil, Inggs afirma que um texto deve ser adaptado ou traduzido "de acordo com o que a sociedade considera (em determinado momento) como educacionalmente 'bom para a criança'; e com um ajuste na trama, na caracterização de personagens e na linguagem para prevalecerem as percepções sociais da habilidade da criança de ler e compreender" ["in accordance with what society regards (at a certain point in time) as educationally 'good for the child'; and an adjustment of plot, characterization, and language to prevailing society's perceptions of the child's ability to read and comprehend"].(Shavit 1986:113 apud Inggs 2015:3).

Na obra de Lobato, há a visão de um mundo leigo no qual não existe contato com qualquer Igreja. É um mundo no qual as crianças são encorajadas a ser independentes, a explorar e a ter contato com o fantástico. São guiadas por Dona Benta, mulher que tem muitas caraterísticas de uma professora universitária aposentada, talvez da História ou das Ciências Sociais, e que encoraja as crianças e bonecos a desenvolver um sentido crítico acerca da história do Brasil, da América Latina e do mundo. Dona Benta insere aulas de vocabulário nas contações de histórias, encoraja as crianças a ler Darwin e chama o Sítio a "Universidade do Pica-pau Amarelo" (Lobato 1968:17). E, especialmente nos anos de 1930, com a publicação de diversos livros didáticos - como Ferro (1931), História do Mundo para as Crianças (1933), Emília no País da Gramática (1934), Aritmética da Emília (1935), Geografia de Dona Benta (1935), História das Invenções (1935), O Escândalo do Petróleo (1936) e O Poço do Visconde (1937) -, "encontramos uma escola alternativa, onde Dona Benta desempenha o papel de professora (...) [e] o sítio se transforma numa grande escola, onde os leitores aprendem desde gramática e aritmética até geologia” (Lajolo 2000:61).

Para Zohar Shavit, um tradutor pode, sim, manipular o textofonte infantil em relação à tradução, desde que siga dois princípios básicos: primeiro, que o livro seja didático, "bom" para a criança; e segundo, que a trama, a linguagem e a caracterização sejam ajustadas à habilidade de leitura da criança (Shavit 1986:112-128 apud Puurtinen 
2006:59). Assim, Lobato adapta Hans Staden e Peter Pan a sua visão de um mundo "bom", que é muito diferente da visão tradicional da Igreja Católica - pela qual o escritor foi severamente criticado. Lobato também usa uma linguagem compreensível para as crianças, evitando expressões rebuscadas, e busca entretê-las.

Em períodos distintos, traduções e adaptações de livros infantis foram influenciadas por elementos políticos, nacionalistas e sociais. Em "Nursery Politics: Sleeping Beauty or the Acculturation of a Tale", Karen Seago ressalta que os Kinder- und Hausmärchen (em tradução livre, Contos para Crianças e Família) dos Irmãos Grimm “originaramse de um forte sentimento de patriotismo alemão em reação à oposição política da ocupação francesa". A "escavação" da literatura tradicional alemã "foi empreendida em um espírito de resistência e como meio de mudança política" (Seago 2006:176). Quando os contos de fadas foram introduzidos na Inglaterra no decorrer do século XIX, foi preciso adaptá-los para livrá-los dos elementos imorais e da frequente crueldade e torná-los conformes com a moralidade vitoriana. Assim, o Sleeping Beauty inglês adapta elementos das versões alemã e francesa, reduzindo conotações eróticas encontradas em ambas as versões e produzindo uma versão que seria aceitável para a classe média britânica: "Na firme submissão do conto em inglês aos valores da classe média de economia e moderação há um insinuação de desaprovação burguesa dos excessos sexuais e financeiros da aristocracia" ["In the English tale's firm allegiance with middle class values of economy and moderation, there is a hint of bourgeois disapproval of the aristocracy's sexual and financial excesses"] (Weeks 1990 apud Seago 2006:181).

Na mesma coletânea, intitulada The Translation of Children's Literature: a Reader, Emer O'Sullivan descreve, em "Does Pinocchio have an Italian passport?", a maneira como o personagem foi adaptado para o alemão no século XIX ${ }^{4}$ : a tradução de Bierbaum voltou a ironia e a sátira de Collodi contra autoridades da Alemanha, satirizando elementos monárquicos, acadêmicos e militares e também o excessivo patriotismo alemão. A comida é alemã, a localização é alemã e referên-

4. De acordo com a Fondazione Collodi (http://www.pinocchio.it/fondazionecollodi/en/ the-adventures-of-pinocchio/), as datas divergem das apresentadas por O'Sullivan. Assim, Otto Julius Bierbaum teria publicado sua versão de Pinóquio sob o título Zapfelkerns Abenteuer em 1905. 
cias à comédia delirante são substituídas por outras, ao Kaspeletheater (O’Sullivan 2006:150).

Nos Estados Unidos, a primeira tradução do boneco que queria ser menino, de Walter S. Cramp, em 19045, seguia as tendências dominantes de moralidade pública, enfatizando a autodisciplina, autonegação, a diligência e o respeito às autoridades e, assim, cortando quaisquer referências à violência, à crítica social e às crianças que ridicularizavam os adultos. O tom é "áspero, punitivo e antipático. Pinóquio, a criança, é uma amolação” (Wunderlich 1992 apud O’Sullivan 2006:151).

Versões subsequentes de Pinóquio restauraram uma personalidade mais simpática do garoto, e O'Sullivan vê a versão da Disney dos anos de 1930 como sendo influenciada pelos eventos da época: a Grande Depressão e a Segunda Grande Guerra que se aproximava. Para este Pinóquio, o objetivo não é crescer e se tornar independente, mas ser um bom menino dentro da família: "A imagem de Pinóquio mudou daquele de Collodi, um menino-marionete egoísta e obstinado, para a personificação da inocência da infância" (O'Sullivan 2006:152).

\section{A Literatura Infantil Política na União Soviética}

Em "Translation and Transformation: English-Language Children's Literature in (Soviet) Russian Guise" Judith Inggs (2015) nota que a literatura infanto-juvenil soviética era um campo restrito, "não diferenciado", conforme Lefevere (1992), em que todas as publicações infanto-juvenis, incluindo as traduções de obras estrangeiras, eram controladas pela Editora Estatal Infantil, conhecida como Detgiz (Detskoe gosudarstvennoe izdatelstvo) e fundada por Maksim Górki, em 1933. Seu objetivo era "instigar nas crianças um interesse pela luta da classe trabalhadora" ["instil in children an interest in the fight for the working class"] (Starza 1984:187 apud Inggs 2015:4), assegurando que uma ideologia comunista fosse instaurada nos jovens leitores. Embora as obras devessem ter qualidade literária, era importante que não houvesse qualquer tipo de conflito com as normas morais e éticas soviéticas, e elas deveriam rejeitar quaisquer opinião racista, chauvinis-

5. Também segundo a Fondazione Collodi, a primeira tradução a sair nos EUA, de Cramp, foi publicada não em 1904, mas em 1901. 
ta, neocolonial ou anticomunista (Motyashov 1976:97-100 apud Inggs 2015:4), dando ênfase a temas militares, patrióticos e revolucionários (Inggs 2011: 83).

Como resultado, muitas obras infanto-juvenis canônicas mantiveram-se desconhecidas do público soviético. Alguns exemplos são Peter Pan (1904) e Mary Poppins (1934), que foram publicadas somente no final dos anos 1960; The Hobbit (1937), The Lion, the Witch and the Wardrobe (1950), que foram publicadas nos anos 1970; e Ann of the Green Gables (1908), que, ainda nos anos de 1990, não havia sido publicada. A partir dos anos 1990, porém, surgiu um grande número de traduções de obras estrangeiras infanto-juvenis, incluindo essas e outras, desconhecidas, como as de Enid Blyton, de Beatrix Potter, e a série de Tarzan (Inggs 2011: 83).

Em "Censorship and Translated Children's Literature in the Soviet Union: The Example of the Wizards $\mathrm{Oz}$ and Goodwin" Inggs (2011) comenta que a recontagem de The Wizard of $O z$ de L.Frank Baum (1900), Volchebnik Izumrudnogo goroda (sem tradução para o português; publicado em inglês como The Wizard of Emerald City), por Aleksandr Volkov (1939), tem inúmeras omissões e acréscimos, enfatizando virtudes tais como a camaradagem e a opressão dos pobres, e desenvolvendo os personagens e dando-lhes chances de mostrar sua lealdade, coragem, força, desenvoltura, humor e fantasia (Inggs 2011: 86). Outro exemplo é a adaptação que Aleksêi Tolstói faz de Pinóquio, de Carlo Collodi, sob o título Zolotôi kliutchk, ili Prikliutchênia Buratino [Золотой ключик, или Приключения Буратино] (em português, A Chave de Ouro, ou Aventuras de Buratino, 1935), que teve que se adaptar às exigências do realismo socialista (Inggs 2015:5).

Inggs destaca a tradução de Robinson Crusoe por Kornêi Tchukóvski, importante tradutor e teórico soviético. Na tradução pre-revolucionária de Maria Chichmarióva, a obra mantinha a promessa do pai de Crusoe de rezar pelo bem-estar do seu filho. Porém, essa referência é omitida na tradução de Tchukóvski. Também são omitidas as reflexões e meditações de Crusoe, em conformidade com o requerimento de que o herói soviético não devia fazer excessivos exames de consciência (Inggs 2015:8-9). A tradução de Tchukóvski ganhou grande prestígio 
e era usada como texto-fonte para outras traduções do bloco soviético (Pokorn 2012:125).

\section{As traduções de Lobato para o russo}

Ao que tudo indica, os primeiros livros de Monteiro Lobato traduzidos para o russo a serem publicados na URSS foram "Histórias de Tia Nastácia", em 1958, e "Sítio do Picapau Amarelo", em 1961. Como acontece com frequência na tradição russo-soviética, estas traduções permanecem intocadas e as publicações posteriores dos mesmos títulos mantêm o conteúdo produzido no final da década de 1950 e início da de 1960. Há indícios, porém, de pelo menos uma tradução de texto não infantil de Monteiro Lobato muito anterior a essas no Arquivo Estatal Russo de Literatura e Artes, segundo documentos inéditos relacionados à tradutora do inglês e do francês Natália PliguinaKamiônskaia (1901-1997) que encontramos no Arquivo Estatal Russo de Literatura e Arte (na sigla em russo, RGALI). Assim, em contrato (RGALI, fundo 611 op 2 ex 167 folha 4) assinado por Kamiônskaia com a Gosizdat (Editora Estatal da República Socialista Federativa Soviética da Rússia), ainda em 1927, ela concede à editora os direitos exclusivos sobre sua tradução de "Sovremenni mutchenik" - em retradução para o português, "Mártir moderno". O documento ainda exige a apresentação da tradução completa e datilografada em 1 de outubro de 1927, e fala em dissolução do contrato em caso de não publicação dois anos após a entrega do material; define o pagamento da tradução completa em 80 rublos e estabelece a tiragem do material em 30.000 exemplares. Há a possibilidade de que o documento se refira, pela data e conteúdo, à tradução de "Um suplício moderno", conto que integra o livro Urupês, de 1918, e apresenta um estafeta, espécie de carteiro, que é burro de carga e submisso a todos e tenta se vingar do chefe após tentar, sem sucesso, pedir demissão. Porém, o contrato também fala em duas "folhas de impressão"6, ou seja, cerca de 80.000 caracteres, e o conto "Um suplício moderno tem apenas pouco mais de 20.000. Três outros documentos por nós localizados no RGALI, datados de 2, 6 e 8 de outubro de 1929 (fundo 611 op 2 ex 167 folhas 7-9), indicam

6. "Petchátni list", em tradução literal, "folha de impressão". Cada uma, com valor especificado no contrato como o equivalente a 40.000 caracteres. 
para o não pagamento da tradução pela Gosizdat, à qual Kamiônskaia exige a quitação por meio da Federação da União (aqui, não Soiuz, mas Obedinenii) dos Escritores Soviéticos. Assim, a obra de Monteiro Lobato já era conhecida, em alguma medida, pelos gatekeepers da intelligentsia soviética desde o final dos anos 1920. A pesquisadora russa da Universidade de Tcherepovets Elena Beliakova sustenta, porém, a recomendação de Jorge Amado teria sido crucial à publicação de Lobato (Beliakova, 2010).

\section{As mudanças nas traduções de Lobato para o russo}

\section{i) Sítio - propriedade particular!}

Em artigo intitulado "Emília vítima da tradução" (1982), Tatiana Belinky (1919-2013), imigrante russa no Brasil, escritora, tradutora e roteirista responsável pela adaptação da obra de Lobato para a televisão, comenta a tradução e adaptação de Reinações de Narizinho para o russo. Ela relata que o livro tem uma

capa amarela, com um rinoceronte puxado por um bonequinho de espiga de milho, de chapéu mexicano na cabeça, e montado por três personagens: uma garotinha, uma boneca magricela de 'rabo-de-cavalo' e um menino, de calças compridas e franjadas e grande 'sombrero' na cabeça. O título do livro e o nome do autor em russo estão dentro de um típico escudo-de-armas, com um pequeno pica-pau amarelinho e os letreiros: 'Monteiru Lobatu' e 'A Ordem do Pica-Pau Amarelo'. (Belinky 1982:25)

Belinky pergunta-se por que o sítio é transformado em uma pequena casa. O começo, no original, era: "Numa casinha branca, lá no Sítio do Pica-Pau Amarelo, mora uma velha de mais de sessenta anos" (Lobato 1980:8). No russo, retraduzido para o português, tornase: "Numa pequena casinha, que nos arredores denominaram, não se sabe por que, de casinha do Pica-Pau Amarelo" (Lobato apud Belinky 1982:25). A grande probabilidade, aventa a escritora, é de que o "sítio" tenha sido eliminado devido ao fato de ser propriedade particular, inaceitável dentro do sistema soviético. Belinky comenta que vários trechos são eliminados, e reflexões acrescentadas. As "asneiras" de Emília, excessivamente individualista, são enfatizadas, e a bondade de 
Tia Nastácia, representante do proletariado, é realçada. Acrescentamse também reflexões de Narizinho, como a seguinte, que não estava no original:

\begin{abstract}
O que assustava Narizinho era outra coisa - aparentemente a boneca tinha um caráter teimoso e atrevido, ela julgava tudo a sua maneira, e ao que parece gostava de falar bobagens. De resto, pensou Narizinho, talvez, talvez seja melhor assim. Já temos duas pessoas inteligentes, vovó e Tia Nastácia. A Emília sempre dirá algo novo, com ela a gente não se entendia... (Lobato apud Belinky 1982:25).
\end{abstract}

Belinky encontra a razão para o livro ser chamado A Ordem do Pica-Pau Amarelo. Se "sítio" era demasiado burguês, fundar uma ordem de cavaleiros não ia ofender sensibilidades de classe. E isto se assemelhava, em alguma medida, a um clube de pioneiros: "Pedrinho sonhou que ele, Pedrinho, fundou na Casinha do Pica-Pau Amarelo uma ordem de cavaleiros, vocês sabem, como os cavaleiros medievais, uma sociedade assim, para todos juntos realizarem grandes feitos... Com ele, Pedrinho, à frente, claro" (Lobato apud Belinky 1982:25).

O livro Orden jioltogo diatla [Орден желтого дятла] (em português, "Ordem do Pica-Pau Amarelo") inclui trechos de Memórias de Emília, além de Reinações de Narizinho. Estudando a tradução mais detalhadamente, constatamos outros elementos cortados, tais como os insultos de Emília aos membros da inteligentsia, filósofos e historiadores, e a eliminação de quase todos os personagens ocidentais que estavam imiscuídos no original, tais como Peter Pan, Tom Mix, Alice, Branca de Neve, Popeye, as crianças inglesas que visitam o Sítio em Memórias de Emília, e claro, a visita a Hollywood no mesmo livro. Gato Félix, curiosamente, é mantido. O anjinho de asa quebrada é transformado em um cavalinho sem $\mathrm{rabo}^{7}$, e a figura do Peter Pan invisível que visita o Sítio nu - já que invisível -, segurando somente uma peninha, e assim passa a ser chamado de Peninha, é mantida (no

7. Ao longo de Orden jioltogo diatla, o cavalinho sem rabo (beskhvostaia lochadka/ бесхвостая лошадка) substitui completamente o anjinho de asa quebrada do original de Memórias de Emília (Lobato, 1978: 14-20). Na tradução, o trecho fica localizado na parte 9 de Orden jioltogo diatla, "Memórias de Emília", capítulo 2 "Graf natchnaet pissat 'Zapiski Emilii'. Kak Emilia davala uroki beskhvostoi lochadke”' [Граф начинает писать «Записки Эмилии»: «Как Эмилия давала уроки бесхвостовой лошадке»], p. 262. 
russo, "Piôrichko") [Пёрышко], mas sem nenhuma menção a seu nome, Peter $\operatorname{Pan}^{8}$ - apesar de se mencionar diversas vezes o uso de "pó de pirlimpimpim" [порошок пирлимпимпим] (Lobato, 1961b: $163,230,254)$.

Apesar das grandes mudanças, comuns na tradução soviética, que segue uma tradição de recontagem e adaptação forte para trazer proximidade do leitor e elementos de domesticação, o volume mantém um enorme estranhamento e estrangeirização, com nomes de frutas e outros elementos exóticos - algo que, assim como no caso das traduções de Jorge Amado para o russo, também se mostrou hábito da escola soviética para determinadas literaturas traduzidas (Darmaros, 2016).

\section{ii) Emília, a bem comportada boneca soviética, e a professora Nastácia}

Os maus modos de Emília, talvez a grande tônica da obra infantil de Lobato, com sua ironia, crueldade, racismo e todo tipo de preconceito, esperteza, egoísmo, bullying e outros elementos politicamente incorretos, são bastante amenizados, da mesma forma que eventual mau comportamento de outros personagens. Assim, a versão soviética mostra os moradores do sítio (ou melhor, "membros da Ordem"), como mais politicamente corretos, moralistas, ensinando um bom comportamento que seria, portanto, inerente à nação brasileira, e seguindo a tradição moralista da literatura infanto-juvenil que vimos na Seção 3. O próprio Lobato como narrador é corrigido pelos soviéticos, como vemos neste trecho, logo no início da obra:

Original: ... tia Nastácia, negra de estimação que carregou Lúcia em pequena (Lobato 1980: 9)

Russo: ... тетушка Настасия, добрая старая негритянка, нянчившая Лусию...” (Lobato 1961a: 4)

Tradução do russo: “...tia Nastácia, a boa e velha negra que cuidava de Lúcia..."

Com a boneca, são infinitas as intervenções. Por exemplo, logo depois do casamento de Emília com Rabicó, os comportamentos de

8. Iniciam-se as menções a "Peninha" na parte 7 da adaptação russa, "A pena do papagaio", capítulo 1, "Voz", p. 155. 
ambos são amenizados, com trechos inteiros cortados. O mau comportamento do Rabicó e o desprezo de Emília por pessoas negras é também suavizado:

Original: - É que estou arrumando minhas malas para me mudar desta casa. Não gosto de velhas, nem brancas nem pretas (Lobato 1980: 139).

Russo: - Нет, я просто складываю чемоданы, потому что собираюсь переехать из этого дома. Здесь меня обижают всякие старухи... (Lobato 1961a: 118)

Tradução do russo: - Não, eu simplesmente estou arrumando as malas porque pretendo me mudar desta casa. Aqui sou ofendida por certas velhas...

São suprimidos trechos em que Emília expressa preconceito de cor contra Tia Nastácia, por exemplo, em "O irmão de Pinocchio", onde diz "não é à toa que ela é preta como carvão" e "essa negra não é fada nenhuma, nem nunca foi branca. Nasceu preta e ainda mais preta há de morrer" (Lobato 1980:138); em Reinações, onde a chama de "negra beiçuda" (Lobato 1978: 79); e em Memórias, onde afirma: "Só não compreendo porque Deus faz uma criatura tão boa e prestimosa nascer preta como carvão" (Lobato 1978: 99-100).

A quintessência da personagem de Emília, sua "esperteza", também é amenizada, com excertos importantes do texto cortados, como a conversa com Visconde no Capítulo X de Memórias: "Aprendi o grande segredo da vida dos homens na terra: a esperteza! Ser esperto é tudo. O mundo é dos espertos. Se eu tivesse um filhinho, dava-lhe um só conselho: Seja esperto, meu filho!" (Lobato 1978: 67) e "É inútil, Visconde lutar contra os espertos. Eles acabam vencendo sempre" (Ibidem).

Na versão russa, ao invés de se gabar de ganhar dinheiro com o trabalho dos outros (já que o Visconde é seu ghost writer), como faz no original ao explicar "esperteza" ("Quem é que fez a Aritmética? Você. Quem ganhou nome e fama? Eu. Quem é que está escrevendo as Memórias? Você. Quem vai ganhar nome e fama? Eu...") (Ibidem), ela questiona a validade disso e se redime:

Russo: - А что вы думаете, граф? Разве мало есть на свете людей, которые делают дела чужими руками и получают деньги за чужую работу, а славу - за чужие идеи? И еще называют это «уметь устраиваться»... 
А я ведь только хочу, чтоб мои записки были получше. (Lobato 1961a: 265)

Tradução do russo: - E o que você acha, Visconde? Será possível que sejam poucas as pessoas no mundo que fazem seu trabalho com as mãos dos outros e recebem dinheiro pelo trabalho dos outros e fama pelas ideias dos outros? E ainda chamam isto de "saber se virar"... Mas eu apenas quero que minhas memórias saiam melhores.

O repetido corte da ideia de "esperteza" é sintomático. O radical e palavras derivadas que melhor substituem "esperteza", "esperto" e derivados em russo, ou seja, "kitrost", "khitri", "khitraia", "khitro", "khitroumni", "khitrets", e até os verbos derivados, "ukhitritsia", no sentido de "dar um jeito", "fazer uma mutreta", e "khitrit" [хитрость, хитрый, хитрая, хитро, хитроумный, хитрец, ухитриться, хитрить] aparecem, no texto vertido por Tinniânova, de maneira muito mais modesta que na obra original - mais precisamente, 11 vezes ao longo do livro todo.

O próprio subcapítulo de Memórias de Emília intitulado "Diálogo entre a boneca e o Visconde. A esperteza da Emília e a resignação do milho" é vertido ao russo como "Mejdu grafom i Emiliei proiskhodit obiasnenie. Nastoitchivaia kukla i pokorni Mais" [Между графом и Эмилией происходит объяснение. Настойчивая кукла и покорный Маис], onde "esperteza" vira "persistência" (traduzido do russo por nós: "Entre o conde e Emília ocorre uma explicação. Boneca persistente e Milho resignado").

A maldade da personagem de pano também é suavizada. No Capítulo XII, por exemplo, Visconde escreve de Emília:

Emília é uma tirana sem coração. Não tem dó de nada. Quando tia Nastácia vai matar um frango, todos correm de perto e tapam os ouvidos. Emília, não. Emília vai assistir. Dá opiniões, acha que o frango não ficou bem matado, manda que tia Nastácia o mate novamente - e outras coisas assim (Lobato 1978: 77).

Na versão russa, porém, a morte não é banalizada e recorrente, e Emília apenas "participa e dá conselhos", apesar de ainda continuar uma "besserdetchnaia tiranka" (Lobato 1962: 268). 
Na obra original, também são mais realçadas as características de Emília como egoísta e interesseira, enquanto "egoistka" e "koristnaia" [эгоистка, корыстная] são palavras que praticamente desaparecem da versão russa - apenas uma vez "egoist" surge (Lobato 1961a: 268) para substituir "interesseira" em: "Também é a criatura mais interesseira do mundo. Só pensa em si, na vidinha dela, nos brinquedos dela. Por isso mesmo está ficando a pessoa mais rica da casa" (Lobato 1978: 77). A versão russa suprime as afirmações seguintes de Visconde de que Emilia rouba dele.

Já Tia Nastácia torna-se mais simpática e não ameaça Emília com palmadas:

Original: - Fazer as pazes com tia Nastácia. A coitada está lá na cozinha chorando de arrependimento de haver ameaçado você com palmadas (Lobato 1980: 140).

Russo: - Что ты попросишь прощения у тетушки Настасий. Я сейчас в кухне была - она очень расстроена, у нее ведь такое доброе сердце - ни с кем ссориться не любит. (Lobato 1961a: 119)

Tradução do russo: - Que você peça desculpas à tia Nastácia. Eu estive na cozinha agora e ela está muito desolada, e ela tem um coração tão bom, não gosta de brigar com ninguém.

A versão russa abranda a maldade da Tia Nastácia, que deixa de matar vários animais, fazendo-o apenas com o peru e o irmão do Rabicó (Lobato 1980:139), e inclui explicação sobre não haver diferença entre as cores das pessoas (Lobato 1961a: 278).

Muito diferente da iletrada Tia Nastácia brasileira, a Nastácia russa mostra preocupação com educação:

Original: Também fui melhorando no resto. Tia Nastácia foi me consertando, e Narizinho também (Lobato 1978: 10).

Russo: В остальном я тоже исправилась. Тетушка Настасия меня много исправляла, и иголкой и воспитанием. Носишка тоже, но больше воспитанием... (Lobato 1961a: 261)

Tradução do russo: No resto eu também me corrigi. A tia Nastácia me corrigiu muito, com a agulha e a educação. A Narizinho também, mas mais com a educação. 
Emília também deixa de ser "mulher de malandro", e corta-se menção a ela sonhar em ser raptada por pirata e mandar no navio (Lobato 1980: 171).

O Peninha, personagem que substitui Peter Pan, também dá lição de moral que não havia no original e fala em prêmios apenas para crianças bem comportadas na parte "Pena de Papagaio". A ênfase da versão russa é no bom comportamento e na necessidade de camaradagem, usando a palavra "tovarisch". Além disso, o Peter Pan disfarçado insiste que não é "baderneiro":

Original: - Viajar comigo pelo mundo das maravilhas. É lá que se tira a prova de quem merece ou não merece este dom das fadas. O primeiro menino invisível que apareceu no mundo foi eu, mas me sinto muito só. Preciso de companheiros. Por isso vim (Lobato 1980: 166).

Russo: - Во-первых, не ругать меня хулиганом. А, во-вторых, поехать со мною в Мир Чудес. Посмотрим, как вы будете себя там вести. Пока что единственный мальчик-невидимка на свете - это я. Но я чувствую себя очень, очень одиноко, мне нужны товарищи. Потому я и пришел сюда. (Lobato 1961a: 157)

Tradução do russo: - Em primeiro lugar, não me chame de baderneiro. Em segundo, vamos comigo ao Mundo das Maravilhas. Vamos ver como vocês irão se comportar lá. Assim, o único menino-invisível na face da Terra sou eu. Mas eu me sinto muito, muito sozinho, e preciso de camaradas [tovarischi]. Por isso vim para cá.

A linguagem tosca e rude é sempre amenizada: por exemplo, cortase o "deixe de ser idiota" do original (Lobato 1980: 170). Some também trecho interessante sobre jogar fora as outras versões "mentirosas" de Cinderela, afirmando que só a dos Grimm está certa (Lobato 1980: 166). Assim, os personagens tornam-se menos fortes, com opiniões menos decididas.

A tradutora russa também torna Pedrinho mais ecológico. Em vez de ir para a floresta derrubar pés de embaúva (Lobato 1980: 87), ele fica olhando a beleza da selva brasileira (Lobato 1961a: 123). E nem mesmo a Tia Nastácia se safa, deixando de cheirar rapé no texto russo na mesma parte do livro.

Dona Benta também tem um ingênuo capítulo incluso em deferência a si. Nele, a velhinha é comparada a uma "fada" que tem uma 
"varinha chamada bondade" que transforma "qualquer fera" em "um ser racional e de maravilhosa alma" (Lobato 1961a: 98).

\section{iii) A inteligentsia soviética}

A tradutora russa de Lobato evita, por meio de cortes e abrandamentos, as referências depreciativas do brasileiro à camada intelectual da sociedade. Este posicionamento é compreensível, já que, com a Revolução de Outubro de 1917, os bolcheviques, ao subirem ao poder, passaram a ver a intelligensia, que antes chamavam de "quartel general da revolução", apenas como "companheiros de viagem que não mereciam confiança" (Mementov e Rastorguiev 2013). Assim, uma verdadeira limpeza nesta camada da sociedade se iniciou por meio de seu exílio a países estrangeiros e regiões distantes. Nos anos 1930 e 1940, porém, aconteceria a verdadeira repressão sobre a velha guarda da intelligensia, pressionada a se submeter a um controle ideológico e, em parte, eliminada - executada, enviada a gulags etc. - pelo Grande Terror de Stálin (enquanto de 1918 à decada de 1920 ela era poupada, ao contrário da intelligensia menchevique e socialista-revolucionária, considerada opositora do bolchevismo). Junto a isto, iniciava-se um programa de preparação de uma "nova intelligentsia", devotada aos ideais do socialismo e propagandeando os pontos de vista do marxismo em todas as esferas da vida.

Assim, seria inconcebível que a intelligentsia mantivesse a depreciação que Lobato faz de sua própria camada da sociedade, mesmo com o início de uma abertura ao movimento de dissidentes a partir de meados dos anos 1950, com o chamado "degelo de Khrushov" engatilhado por seu discurso secreto de 1956. Isto fica patente na tradução de Lobato para o russo de 1961, onde, por exemplo, a versão russa corta a referência a "futuros historiadores, gente muito mexeriqueira" (Lobato 1978: 10), ou quando a boneca Emilia é distanciada da filosofia:

Original: Sei dizer coisas engraçadas e até filosóficas (Lobato 1978: 10). Russo: Я умею говорить вещи разумные и остроумные... (Lobato 1961a: 261)

Tradução do russo: Eu sei dizer coisas sensatas e espirituosas...

Em seguida, é suprimido todo um trecho depreciando a figura do filósofo, qualificando-o como "um bicho sujinho, caspento, que diz 
coisas elevadas que os outros julgam que entendem" (Lobato 1978: 13), assim como a ideia de que Emília estaria sendo "filosófica":

Aquela explicação era positivamente filosófica.

— E como sou filósofa - continuou Emília - quero que minhas Memórias comecem com a minha filosofia da vida. (Lobato 1978: 13)

O mesmo acontece com a conclusão a que Emília chega: "Está vendo como é filosófica a minha ideia?" (Lobato 1978: 13).

\section{iv) Peter Pan e Hollywood}

Referências ao mundo cultural anglófono foram, em geral, apagadas ou maquiadas na obra de Lobato traduzida para o russo. As histórias de Peter Pan, por exemplo, permanecem, mas o personagem nunca é chamado pelo nome, mas sim de "Peninha" (em russo, "Piôrichko") [Пёрышко]. O fato é compreensível, já que as obras de Lobato foram publicadas na URSS entre 1958 e 1961, e Peter Pan foi um personagem censurado nas prensas soviéticas até 1968 (após um longo hiato, é neste ano que ele volta a ser publicado no país). Antes disto, o livro Bélaia Ptitchka [Белая птичка] (em inglês, The Little White Bird), que introduz pela primeira vez Peter Pan, já havia sido vertido ao russo pela tradutora Avgusta Filippovna Damanskaia (1877-1959) e publicado no país entre 1918 e $1923^{\circ}$. A tradução que é finalmente permitida em 1968 é de autoria de Nina Demurova, e considerada exemplar, comparada à tradição soviética:

Pode-se dizer que o leitor russófono tem alguma ideia da literatura infantil vitoriana graças a Nina Demurova, que ignorou completamente os costumes para a prática soviética de estratégias de adaptação e deixou na literatura inglesa do século 19 e começo do 20 toda sua inerente complexidade, tristeza, sentimentalismo e excentricidade (Borisenko 2017).

A verdade é que, para chegar a este resultado, Demurova teve que esperar 12 anos com o livro na gaveta e fazer muitos contatos. Suas atividades em prol da publicação de Peter Pan reforçam nossa

9. Ver: BARRIE J.M. Belaia ptitchka. Petersburgo: Gosudarstvennoie izdatelstvo, 1922. e BARRIE J. M. Belaia ptitchka. Berlim: Ogonki, 1923. 
teoria de que os tradutores tiveram sua parcela de influência - por vezes, de peso - no gatekeeping editorial soviético. Sobre a censura a Peter Pan e sua luta pela a publicação da obra, que só ocorre no final dos anos 1960, a própria Demurova disse, em entrevista à revista "Vopróssi literaturi":

\footnotetext{
Não publicavam o livro - já que ele não parecia em nada com os livros de então para crianças. A editora 'Détskaia literatura' parecia querer pegá-lo, mas, apesar disto, a editora disse que este romance não era para crianças soviéticas: o menino, por algum motivo voava, mister e misses Darling contrataram como babá das crianças um cachorro; a menina Liza serve a eles como criada, e isto não é nada diferente de exploração do trabalho infantil... (...) Desesperada, fui pedir ajuda a Kornêi Ivanovitch Tchukóvski. [Ele] escreveu uma carta à editora onde, de maneira bastante irônica, disse: deixem que as crianças soviéticas saibam que até gente boa como os Darling, na Inglaterra, explorava o trabalho infantil. No final das contas, depois de ficar engavetado por quase doze anos, a tradução saiu com um mínimo de cortes (Demurova 2001).
}

Mas na adaptação que Inna Tiniânova faz de Sítio do Picapau Amarelo, anterior à publicação de Demurova, as histórias que contêm o personagem se mantêm - mesmo que, como já dito anteriormente, tenha seu nome alterado para "Peninha". Isto não impede, porém, o pó de pirlimpimpim de aparecer.

Assim, toda a parte central de Memórias é omitida: o Rei da Inglaterra mandando ao Sítio de Dona Benta um navio cheio de crianças sob o comando do Almirante Brown no capítulo III; a aparência e designação de Peter Pan; o anjo falso e anjinho verdadeiro no capítulo IV; a visita de Popeye, que espanca capitão Gancho e que briga com Pedrinho e Peter Pan nos Capítulos VI, VII, VIII e IX; a despedida dos visitantes no capítulo I; a passagem de Narizinho e Emília por Hollywood, onde visitam Shirley Temple, nos capítulos XI, XII, XIII e XIV. O texto russo somente retoma Memórias com o capítulo X, "Diálogo entre a boneca e o Visconde. A esperteza da Emília e a resignação do Milho", e parte do XII, sobre o desabafo do Visconde, e do último Capítulo, "Últimas impressões de Emília, suas ideias sobre pessoas e coisas do sítio de Dona Benta". 
O personagem Sherlock Holmes, porém, é mantido - o detetive chegou a ganhar nada menos que sete adaptações soviéticas a partir de 1968, apesar de seu caráter burguês ser frequentemente enfatizado por críticos, entre eles Kornêi Tchukóvski. Assim como ele, os episódios com Gato Felix permanecem, apesar de ele ter sido um importante símbolo da cultura norte-americana dos anos 1920. Pouco se sabe, porém, sobre sua presença na URSS à época, e não pudemos localizar textos sobre o assunto em russo e em inglês. Nos EUA, porém, Felix se tornou mascote de diversas divisões militares, universidades e até um grupo musical foi batizado em sua homenagem. Além disto, o desenho deu amplo espaço à dança e ao jazz, ritmo que teve uma recepção hesitante na URSS - ora estimulado, como música de uma minoria afroamericana oprimida e instrumento de luta política, ora proibido, visto como símbolo da cultura burguesa (Egorov 2017). Já uma menção ao cowboy Tom Mix, quando Lobato escreve que Félix é tão forte que derrota até o ator de faroeste, também desaparece da versão russa.

\section{v) Religião e referências burguesas, capitalistas e religiosas}

Enquanto o Felix do Lobato russo conta suas aventuras, muita coisa é mantida: a descoberta da América por Colombo, referências aos Estados Unidos e outros países etc. Porém, o "profeta Jonas, que 'permaneceu' uma porção de tempo dentro da barriga de um peixe" vira "um homem que foi parar na barriga de uma baleia" (Lobato 1961a: 55) e é cortada uma simples menção a São Pedro, que segundo Emília ficaria furioso com a altura dos arranha-céus.

O anjinho de asa quebrada de Memórias também é suprimido, transformando-se no cavalinho sem rabo que aparece em Reinações. Em outro trecho ela também, claro, deixa de se parecer com "um judas no Sábado de Aleluia". O Jesus Cristo mencionado por Emília quando ela começa a escrever suas Memórias também é eliminado da versão russa.

Além dos cortes religiosos há a supressão de determinados elementos capitalistas. Por exemplo, quando Rabicó e Emília se casam e o porco usa uma cartola, cai no russo a referência ao acessório, que é um dos principais símbolos do capitalismo, junto com a menção ao padre que os casa e a diversas outras a príncipes e princesas (Lobato 1980:65-66). No caso do Visconde de Sabugosa, 
que tem a cartola como elemento-chave de seu figurino, ela nunca é mencionada, sempre apontada como uma "chliapa", ou seja, um simples chapéu. Em "O irmão de Pinóquio" é cortada até mesmo a referência à "sala de jantar", cômodo que era considerado uma excentricidade dos ricos na União Soviética - e continua a ser até mesmo na Rússia atual. E em "Pena de Papagaio - O Senhor de La Fontaine", suprime-se menção à fábula da cigarra, que louva o sistema econômico liberal.

\section{vi) Referências exóticas, estrangeirismos, (pseudo)localização}

A versão russa de Lobato realizada por Inna Tiniânova repete um padrão já identificado nas traduções de Amado para o russo, a partir dos anos 1940: a de se manterem elementos estrangeirizantes no texto de chegada. Assim, a tradução, por exemplo, de Gabriela, Cravo e Canela para o russo em 1962, por Iúri Kaluguin, mantém muitas vezes sem explicações ou notas de rodapé, apenas transliterados, elementos como "caxixe" [кашише] - tão alienígenas até mesmo para brasileiros de outras regiões que não a Bahia -, mas também outros, facilmente traduzíveis, como "mingau” [мингау] (Darmaros 2016: 240).

A obra de Lobato vertida por Tiniânova também introduz muitos elementos transliterados, como "pitanga", "jabuticaba", "lambari", "caju", "maracujá", e até o "ingazeiro" vira "dêrevo inga" ("árvore de ingá") [питанга, жабутикаба, ламбари, кажу, маракужа, дерево инга]. A tendência talvez possa ser explicada pelos esforços de se explicitar a existência e reafirmar o alinhamento da literatura estrangeira. Da mesma forma, de acordo com a pesquisadora Susanna Witt, pseudotradutores de literatura das repúblicas soviéticas para o russo "mantinham" elementos estrangeirizantes (Witt 2013: 149) - neste caso, porém, tratavam-se na realidade de autores completamente criados por "tradutores" russos, ou seja, escritores oficiais da URSS responsáveis por inventar esses personagens e sua "literatura estrangeira vertida ao russo", como foi o caso dos cazaques Djambul Djabaev e Maimbet.

Em outros trechos, expressões idiomáticas são traduzidas ao pé da letra, como é o caso de "voz de taquara rachada", que em russo torna-se "skriputchii golosok, slovno eto skripit nadstresnuti strebel bambuka" [скрипучий голосок, словно это скрипит надтреснутый стебель бамбука] (Lobato 1961a: 107). A comparação, claro, não 
existe em russo, mas a tradutora consegue imprimir a ela algum sentido estendendo-a (retraduzindo ao pé da letra, ela verte o trecho para "[ela inventou] uma vozinha que rangia exatamente como range uma haste rachada de bambu".

Também verificamos a criação de um folclore indígena para substituir referências religiosas, seguindo bastante a linha analisada por Witt supracitada:

Original: [Visconde fala:] — Deus deu vida ao primeiro homem fazendo um boneco de barro e assoprando. (Lobato 1980: 141)

Russo: - Я держусь того мнения, что, для того чтобы брат Буратино ожил и получил дар речи, надо на него дуть. В древних сказаниях индейцев Бразилии часто встречается такой мотив: когда подуешь на мертвое тело, то оно оживает. Я держусь того мнения, что... (Lobato 1961a: 120)

Tradução do russo: - Eu defendo a opinião de que, para que o irmão de Buratino ganhasse vida e recebesse o dom da fala, era preciso soprá-lo. Nos contos antigos dos indígenas do Brasil, é comum encontrar este tema: quando você sopra um corpo morto, ele ressuscita. Eu defendo a opinião de que...

\section{Palavras Finais}

As versões russas tiveram um papel de versões intermediárias, a partir das quais outras traduções foram feitas para as línguas das repúblicas da União Soviética e também de outros países comunistas. Por exemplo, Reinações de Narizinho (Przygody Narizinii czyli Zadartego noska), traduzido por Janina Wrozskowa, foi publicado na Polônia em 1976 pela Nasza Ksiegarnia, uma editora importante que lançou muitos livros infantis. Dois contos de Lobato também foram traduzidos ali: "Niewolnicy" ("Os Negros"), e "Klęska mrozu Bluszcz" ("O Drama da Geada"), ambos retirados de Negrinha, traduzidos por J. Świerczewskiej, Warszawa e publicados pela editora Towarzystwo Wydawnicze 'Bluszcz', em 1928.

Na China, O Picapau Amarelo e A Reforma da Natureza, publicados juntos pela Editora Brasiliense, foram lançados em 1982 como A Pequena Convidada no País dos Contos de Fadas (童话国的小客 人). Com tradução de Youjun Sun (孙幼军), escritora de literatura 
infanto-juvenil na China pela Editora Xinlei (新蕾出版社), a obra teve intermédio da versão russa, e sua segunda edição foi publicada pela Editora do Século XXI (二十一世纪出版社), em 2007.

Os Contos de Tia Anastácia (娜丝塔霞姑姑讲的故事) (As Histórias de Tia Nastácia), traduzidos por Yang Yong e Yang Tao (杨永/ 杨涛) foram publicados pela Editora Juvenil e Infantil (少年儿童出 版社), em 1959. O livro A Narizinho Travessa (淘气的小鼻子) ( $A s$ Reinações de Narizinho), foi traduzido por Shulien Li et alli (李淑廉等) e publicado pela instituição pública Editora China de Rádio e Televisão (中国广播电视出版社), em 1990. Já $O$ Espirito da Árvore (树精) ( $O$ Saci) também foi traduzido por Shulien Li \& Yilan Ong (李淑廉翁怡 兰), em 1990, possivelmente a partir da tradução argentina.

Na Letônia, Reinações de Narizinho foi originalmente publicado pela Editora Latvijas Valsts Izdevnieciba, em 1964, com tradução de Evalds Juhnevics. Ali, ele foi reeditado, em 1976, pela Editora Liesma. Mais tarde, após a queda com comunismo e com Letônia já reconhecida como país independente, a obra foi lançada pela hoje extinta editora Junikom Izdevnieciba, em 2004, com tradução de Iveta Paegle. Evalds Juhnevics também traduziu Histórias de Tia Nastácia, em 1966, pela Editora Liesma, e a obra foi reeditada pela Editora APGADS, em 1999. Da mesma forma, Reinações foi traduzido para o estoniano, em 1964, pela Eesti Riiklik Kirjastus, com tradução de Hilja Välipõllu, baseada na versão de Tinniânova - até as ilustrações são as mesmas. As mesmas obras foram traduzidas ainda para o ucraniano: Reinações, em 1964, pela Editora Veselka, Kiev, com tradução de Vladimir Bulat, e Histórias de Tia Nastácia, em 1977, aparentemente vertida do português por Michalla Litvinchya, também pela Editora Veselka, Kiev.

Além disso, existe uma versão em tibetano de Reinações, Livro para crianças em Língua Tibetana, 1993, publicado e traduzido pela "Tibet Autonomous Region Party Committee, General Office of Translation and Interpretation, Ethnic Publishing House, Beijing".

E, afinal, era Lobato comunista ou não? Stalinista? Talvez trotskista? Ênio Silveira faz um delicioso relato sobre a ideologia de Lobato - e como esta era percebida por outras pessoas - ao descrever o enterro do escritor, em 5 de julho de 1948, um dia após sua morte. Ao contar como a multidão já o aguardava, no cemitério, subir a Avenida da Con- 
solação, Silveira diz que Lobato era bastante amigo dos comunistas, mas também era seguidor do espiritismo e comparecia às Sociedades Espíritas para fazer contato com seus dois filhos mortos. Além disto, era barão rural, membro da aristocracia rural e...

Também membro de uma Sociedade Agrícola de São Paulo, do Clube Piratininga e outras coisas que reuniam a aristocracia rural paulista. Era também bom escritor, portanto tinha a sua grei de escritor-jornalista. Ali, "namorava" também alguns trotskistas, que por isso o julgavam trotskista. Bom, então, esta fauna diversa, multifacetada, se reuniu ali, à beira do túmulo. Quando iam descer o corpo, um pouco antes, pediu a palavra arrebatadamente o Rossini Camargo, poeta, membro do partido:

- Camarada Lobato - era ditadura, o partido era ilegal —, estamos aqui, teus irmãos, não apenas para chorar por ti, mas para dizer que jamais morrerás, que estarás vivo na consciência do povo, no coração do povo como batalhador, como um companheiro...

- Perdão, companheiro não! Lobato era trotskista - era o professor Phebus Gikovate. - Canalha, filho da puta...

Principiaram as cenas de pugilato, socos, caíram os dois, e rolaram no chão, o Gikovate e o Camargo Guarnieri caíram na cova aberta. Uma cena de filme de Fellini. Quando tiraram os dois, um sujeito do Clube Piratininga disse assim:

- Não, o senhor era da fina aristocracia, se tivéssemos ainda o Império, ele seria um nobre, nobre por dentro e por fora, Lobato... (Pires Ferreira 1992:45).

\section{Referências}

BELIAKOVA, Elena. 2010. Russki Amadu i brazilskaia literatura v Rossii. Moscou: ILA RAN. Moscow: ILA-RAN.

BELINKY, Tatiana. "Emília vítima da tradução". Folha de S. Paulo. São Paulo, 18 jan.1982. Ilustrada. p. 25.

BERTOLINO, Osvaldo 2012. "Bertolino: Monteiro Lobato e o Partido Comunista do Brasil”. Portal Vermelho, 04/03/2012. Disponível em: http://www.vermelho.org.br/noticia.php?id_noticia=177032. Acesso em: 26/08/2018.

BORISENKO, Aleksandra. 2017. "Istoria Pitera Pana", em Academia Arzamas, 09/11/2017. Disponível em: https://arzamas.academy/ mag/466-peter. Acesso em: 14/06/2019.

CARTER, Rosemary de Paula Leite. 2011. "Little Blue Books no. 733 - Brazilian Short Stories, A Relação entre o Escritor Brasileiro 
Monteiro Lobato e o Norte-americano Issac Goldberg", XII Congresso Internacional da ABRALIC - Centro, Centros - Ética, Estética. 18 a 22 de julho de 2011, UFPR - Curitiba, Brasil. Disponível em: http:// docplayer.com.br/36216269-Little-blue-books-no733-brazilian-shortstories-a-relacao-entre-o-escritor-brasileiro-monteiro-lobato-e-onorte-americano-isaac-goldberg.html. Acesso em: 14/06/2019.

CAVALHEIRO, Edgar. 1955. Monteiro Lobato - Vida e Obra (2 vols.). São Paulo: Companhia Distribuidora Nacional.

DALLARI, Dalmo de Abreu. 1994. "A ilusão do imposto único", em Folha de S. Paulo, 30 de setembro de 1994. Disponível em: https:// www1.folha.uol.com.br/fsp/1994/9/30/dinheiro/4.html. Acesso em: 14/06/2019.

DARMAROS, Marina Fonseca. 2016. Por que ler Jorge Amado em russo: a cultura soviética revelada na tradução de Gabriela. TradTerm, v. 28, p. 223-248, 2016. Disponível em: http://www.revistas.usp.br/ tradterm/article/view/125561. Acesso em: 14/06/2019.

DEMUROVA, Nina. 2009."V Rossii interes k Kerrollu takoi zhe, kak v Anglii, a vozmozhno, i bolshe...". Voprosi Literaturi 2 (2009). Disponível em: http://magazines.russ.ru/voplit/2009/2/de16-pr. html. Acesso em: 14/06/2019.

EGOROV, Boris. 2018. "As idas e vindas do jazz norte-americano na União Soviética”. Gazeta Russa, 17/11/2018. Disponível em: https:// br.rbth.com/historia/81498-idas-vindas-jazz-americano-urss. Acesso em: 14/06/2019.

FERREIRA, Jerusa Pires; ALMEIDA, Marta Assis de (org.). 1992. Ênio Silveira. São Paulo: EdUSP, 1992.

INGGS, Judith A. 2011. "Censorship and Translated Children's Literature in the Soviet Union: The Example of the Wizards Oz and Goodwin". Target 23.1 (2011): 77-91. 2015. "Translation and Transformation: English-Language Children's Literature in (Soviet) Russian Guise". International Research in Children's Literature 8.1 (2015): 1-16. Edinburgh University Press.

KLINGBERG. Göte. 1986. Children's Fiction in the Hands of the Translators. Lund: CWK Gleerup.

LAJOLO, Marisa. 2000. Monteiro Lobato: Um Brasileiro sob Medida. São Paulo: Moderna.

LATHEY, Gillian. 2010. The Role of Translators in Children's Literature: Invisible Storytellers. New York and London: Routledge.

LEFEVERE, André. 1992. Translation, Rewriting and the Manipulation of Literary Fame. London and New York: Routledge. 
LOBATO, Monteiro. 1948. O Impôsto Único. São Paulo: Brasiliense.

LOBATO, Monteiro. 1961a. Orden jioltogo diatla. Moscou:

Gosudarstvennoe Izdatelstvo Detskoi Literaturi. 288 p. . 1961b. Orden jiôltogo diatla. Moscou: Detguiz. . 1962 (1921). Fábulas. 19ed. São Paulo: Brasiliense. .1968 (1937). Histórias de Tia Nastácia. 13ed. São Paulo: Brasiliense. . 1978 (1936). Memórias da Emília. 29a ed. São Paulo: Brasiliense.

. 1980 (1931). Reinações de Narizinho. 31a ed. São Paulo: Brasiliense. 2008 (1927). Mister Slang e o Brasil. São Paulo: Globo.

MEMENTOV, V.S., RASTORGUIEV, V.N. "Intelligêntsia". 2013. Bolchaia rossiskaia entsiklopedia. Disponível em: https://bigenc.ru/ domestic_history/text/2013995. Acesso em 14/06/2019.

MOTYASHOV, I. 1976. "The Social and Aesthetic Criteria Applied in Choosing Children's Books for Translation". In: Göte Klingberg, Mary Ørvig, Stuart Amor (eds.). Children's Books in Translation: The Situation and the Problems. Stockholm: Almqvist \& Wiksell International. p. 96-103.

O’SULLIVAN, Emer. 2006. "Does Pinocchio have an Italian Passport? What is Specifically National and what is International about Classics of Childrens Literature". In: Gillian Lathey (ed.). The Translation of Children's Literature: A Reader. Clevedon: Multilingual Matters. p. 146-162.

POKORN, Nike K. 2012. Post-Socialist Translation Practices: Ideological struggle in children's literature. Amsterdam: John Benjamins.

PUURTINEN, Tiina. 2006. "Translating Children's Literature: Theoretical Approaches and Empirical Studies". In: Gillian Lathey (ed.). The Translation of Children's Literature: A Reader. Clevedon: Multilingual Matters. p. 54-64.

SEAGO, Karen. 2006. "Nursery Politics: Sleeping Beauty or the Acculturation of a Tale". In: Gillian Lathey (ed.). The Translation of Children's Literature: A Reader. Clevedon: Multilingual Matters. p. 175-189.

SHAVIT, Zohar. 2006. Poetics of Children's Literature. Georgia: University of Georgia Press.

STARZA, Arleta. 1984. Children's Literature in the Soviet Union: $1917-$ 1934. PhD thesis. Nottingham: University of Nottingham.

WEEKS, J. 1990. Sex, Politics and Society. The Regulation of Sexuality since 1800. 2nd ed. New York: Longman. 
WITT, Susanna. 2013. "Arts of Accommodation: The First All-Union Conference of Translators, Moscow, 1936, and the Ideologization of Norms". In: Leon Burnett and Emily Lygo (eds.). The Art of Accommodation: Literary Translation in Russia. Bern: Peter Lang. p. 141-184.

WUNDERLICH, R. 1992. "The tribulations of Pinocchio: How social change can wreck a good story". Poetics Today 13 (2), 197-219.

Recebido em: 24/11/2018

Aprovado em: 10/01/2019 